\title{
BANK MANAGEMENT AND MARKET DISCIPLINE
}

\author{
Yoram Landskroner ${ }^{a}$ and Jacob Paroush ${ }^{b}$
}

October 2003

\begin{abstract}
In recent years market discipline attracted interest as a mechanism to augment or to partially replace government oversight (discipline) of the financial sector, specifically depository institutions. Despite the abundance of research, mostly empirical studies, in the area no formal model has been presented to analyze the different aspects of the issue. This paper attempts to fill this gap. In our model we incorporate the characteristics of the regulatory structure and market discipline and examine the effects of several parameters on the optimal decisions of the bank. For example we consider the effects of changes in risk, deposit insurance coverage, and degree of market discipline. In most cases our results are compatible with recent empirical findings.
\end{abstract}

Key words: market discipline, bank failure, bank asset-liability Bank Failure Bank management, deposit insurance, risk premium, We would like to thank Larry Goldberg and Paul Wachtel for their comments.

a. School of Business Administration, Hebrew University of Jerusalem and Stern School of Business, NYU. E-mail: ylandskr@stern.nyu.edu

b. Economics department, Bar-Illan University and Ashkelon Academic College. E-mail:parousj@mail.biu.ac.il 


\section{BANK MANAGEMENT AND MARKET DISCIPLINE}

\section{Introduction}

The stakeholders in a firm can monitor and control behavior through the use of market mechanisms .The ability to influence the cost and quantity of funds available to the firm, as well as the valuation of its assets, provides a market-based structure for corporate governance (market discipline). Market discipline is considered optimal for corporate governance as is evident in unregulated industries. This paradigm for governance, in particular by debtholders may not apply to financial institutions, especially depository institutions. Most of the liabilities of thrifts are not traded in the market so debtholders lack opportunities to exercise market discipline. Moreover, the government that provides much of the governance of these institutions through regulatory and supervisory mechanisms also guarantees a large part of the liabilities of depositories. Specifically, because of deposit insurance, depositors have no incentive to monitor the bank. This asymmetry has been widely noted and many observers have asked how market discipline can be applied to financial institutions. Although many suggestions have been made, there is no modeling framework for evaluating them. In this paper, we analyze market discipline in the context of optimal bank behavior.

Depository institutions are highly regulated to protect against the disruption of the unique services they provide to avoid the social costs (negative externalities) this would impose on the economy. One of the main goals of regulation and supervision is to promote the safety and soundness of the financial system ${ }^{1}$. In the last decades there has been increased financial instability in the form financial crises including banking and currency crises in many countries ${ }^{2}$. It seems that traditional regulatory mechanisms are

\footnotetext{
${ }^{1}$ See Paroush (1988) on the domino effect and the need for supervision in banking.

${ }^{2}$ See Williamson (2001) for a review of a volume of reports on financial crisis including banking and currency crises: Krugman, Paul ed. Currency crises. NBER Conference Report series. University of Chicago Press, 2000.
} 
either not well applied or do not suffice, see Demirguc-Kunt and Detragiache (1999) who find that deposit insurance is detrimental to bank stability. ${ }^{3}$

As a result of these developments market discipline attracted the interest of academics, regulators and bankers as a mechanism to augment or to a certain degree replace government oversight of the financial sector. The third pillar (element) of the proposed new Basel Capital banking Accord (Basel II) is market discipline. ” The committee emphasizes the potential for market discipline to reinforce capital regulation and other supervisory efforts in promoting safety and soundness in banks and financial system"4.

The literature on market discipline in banking is limited to a policy literature that discusses various proposals, such as mandatory subordinated debt See Crockett (2002) and an empirical literature that looks at the effect of bank risk on some available market measures, for a review of U.S. empirical evidence see Flannery (1998). However, there is no theoretical framework that analyzes the different aspects of the incorporation of market discipline into corporate governance of financial institutions, and that offers insights and solutions to the different issues, such as how to model market discipline and measure its effect, effects of a change in regulation or risk faced by the institution. This paper attempts to fill this gap by modeling market discipline in a framework of optimal bank behavior.

Our model, in which the bank is assumed to maximize expected profits, incorporates the characteristics of the regulatory structure and market discipline. Market discipline is considered here as the "direct” effect of the risk of the bank's assets and its capital structure on the cost of its uninsured funds. We define the degree of market discipline to be the sensitivity of the cost of uninsured deposits with respect to the capital structure adjusted for the risk of the bank. Government regulation is introduced via deposit insurance provided to part of the depositors. The model enables us to examine and derive the effects of several parameters on the bank and compare these to empirical

\footnotetext{
${ }^{3}$ In the U.S. the savings and loans crisis of the 1980s demonstrated how forbearance of the supervisor could increase the cost of a crisis. As a result the FDICIA of 1991 mandated least cost resolution of failing banks and prompt corrective action by the FDIC.

${ }^{4}$ That is market discipline, to be facilitated by disclosure of meaningful information by banks, is supposed to augment regulatory discipline. See Basle Committee on Banking Supervision (2001).

${ }^{5}$ See for example Sundaresan (2001) who examines the desirability of incorporating market discipline in bank supervision and regulation. And explores the use of equity prices as signals of bank credit risk.
} 
findings. We consider the effects of a change in risk of the bank, deposit insurance coverage and price, degree of market discipline, on the optimal behavior of the bank, such as the optimal quantities of insured and uninsured deposits. In most cases the results are compatible with existing empirical findings and thus the model can serve as a theoretical framework for explaining bank management decisions and the effects of market discipline.

Market discipline has a number of definitions in the literature, Kwast et al. (1999) distinguishes between "direct" and "indirect" effects of the market. The "direct" effect is when investors can influence the risk taking of the bank by affecting the cost and/or quantity of funds; Flannery (2001) refers to this as "market influence”. This is the definition used in this paper. The interaction of the supervisor's information with that of the market is refereed to as the "indirect effect".

The paper is organized as follows: section II presents a model of a bank that manages only its liabilities (assets are assumed fixed). We derive equilibrium values from the first order conditions as well as results of comparative statics analysis with respect to a number of parameters of our model. In Section III we relax the assumption of fixed assets and consider a bank that manages both its assets and liabilities (ALM). In both sections the results are calibrated with empirical findings. The main results and concluding remarks are presented in section IV. 


\section{The Liability Management Model}

We start with a bank whose optimal decision about its assets has already been made and they are now fixed, thus the bank only manages its liabilities. The bank has two types of liabilities: insured deposits and uninsured large deposits, ${ }^{6}$ and is assumed to pay a deposit insurance premium on its total deposits ${ }^{7}$. Market discipline is introduced through a risk premium charged by the uninsured bank debtholders. The risk premium can be considered a function of the risk of the assets of the bank and its leverage measured by the equity capital ratio of the bank and where equity serves as a cushion against future losses. Thus market discipline is modeled in our analysis as the effect of the bank's risk and capital structure on the cost of its funds. This is referred to in the literature as the “direct” effect of market discipline, see Kwast et al. (1999). The rates and quantities of the two types of deposits are assumed to be determined in two separate markets. In the more competitive and less regulated uninsured deposits market (national or even international market) the bank is assumed to face an infinitely elastic supply function ${ }^{8}$; while the insured deposits market ("local market" of households and small business) is less competitive due also to regulation that restricts competition, like the restrictions on branching and interstate banking that existed until recently in the USA. In this market we assume that the supply curve of deposits is positively slopped. In addition the bank has equity capital and faces an increasing cost of raising equity. Because of uncertainty about the value of the assets of the bank and the capital structure of the bank (equity capital not enough to offset the decline in asset value relative to liabilities) the bank may fail with some positive probability. This probability of insolvency may thus be considered a function of two variables: the risk of the assets of the bank and the financial leverage of the bank.

\footnotetext{
${ }^{6}$ We do not consider explicitly non -deposit liabilities like federal funds and repurchase agreements. They are short term, inter-bank transactions and as such are not very relevant to the main issue of our paper namely market discipline. Non-deposit liabilities (borrowings and other liabilities) total $26.8 \%$ of all bank liabilities in the U.S. (FDIC December 31, 2000)

${ }^{7}$ Currently the FDIC insures deposits up to a limit of $\$ 100,000$. The insurance premium however is paid on all domestic deposits of all sizes.

${ }^{8}$ Uninsured deposits are large-denominated deposits held mostly by corporations, mutual funds and other financial institutions
} 
The (expected) net income (NI) function of the bank can now be written ${ }^{9}$ :

$$
N I=P(E)\left\{r_{L} L-\left[r_{0} D_{0}\left(r_{0}\right)+r_{1}(E) D_{1}\right]\right\}-\lambda\left(D_{0}\left(r_{0}\right)+D_{1}\right)-k(E)-C(L)
$$

At this stage of the analysis the asset composition is assumed to be given, as the bank is only managing its liabilities, $r_{L}$ is the interest rate on the fixed loans of the bank $L$. Where $\mathrm{P}$ is the probability of survival of the bank, (1-P) is the probability of the bank's insolvency. Given that $\mathrm{L}$ is fixed the probability of survival is assumed to be an increasing function of the equity capital of the bank $E$ which serves as a cushion against future losses of the bank; $r_{0}$ is the interest rate on the insured deposits $D_{0}$ which denotes the supply function of deposits and is increasing in $r_{0}$; $r_{1}$ is the interest rate on the uninsured deposits $\mathrm{D}_{1}$, which includes a risk premium that is an inverse function of equity capital E. In other words the uninsured depositors exercise their market discipline via the required interest rate on their deposits. If the bank's equity is lowered and consequently the probability of insolvency (1-P) is increased the interest rate $\mathrm{r}_{1}$ will also increase. The parameter $\lambda$ is the deposit insurance premium rate charged on all deposits; $\mathrm{k}$ is the cost of equity capital and is an increasing function of E. The operating cost $\mathrm{C}(\mathrm{L})$ is a fixed cost as long as $\mathrm{L}$ is constant.

The budget (balance sheet) constraint is: $\mathrm{L}=\mathrm{D}_{0}\left(\mathrm{r}_{0}\right)+\mathrm{D}_{1}+\mathrm{E}$. Since $\mathrm{L}$ is fixed, the uninsured deposits $\mathrm{D}_{1}$ are by definition the residual liability that equates both sides of the balance sheet:

$D_{1}=L-D_{0}\left(r_{0}\right)-E$

The market for uninsured deposits is significantly more competitive than the insured deposits market, we assume for simplicity without loss of generality that the supply function of uninsured deposits is infinitely elastic for every $r_{1}$.

Assuming risk neutrality the objective of the bank is to maximize its expected net income NI w.r.t $E$ and $r_{0}$ subject to the budget constrain. Substituting (2) in (1) we obtain NI as an unconstrained target function:

\footnotetext{
${ }^{9}$ In case of failure we assume $\mathrm{NI}=0$.
} 


$$
N I=P(E)\left\{r_{L} L-\left[r_{0} D_{0}\left(r_{0}\right)+r_{1}(E)\left(L-D_{0}\left(r_{0}\right)-E\right)\right]\right\}-\lambda(L-E)-k(E)-C(L)
$$

Note that since total assets are fixed total deposits decline as equity E increases.

We will now derive the first order conditions for the two decision variables of the bank: E and $\mathrm{r}_{0}$. First differentiate the objective function w.r.t. E:

$$
\frac{\partial N I}{\partial E}=\frac{d P}{d E} \Pi+P \frac{\partial \Pi}{\partial E}+\lambda-\frac{d k}{d E}=0
$$

Where $\Pi$ is the net interest income (NII):

$$
\Pi=r_{L} L-\left[r_{0} D_{0}\left(r_{0}\right)+r_{1}(E) D_{1}\right]
$$

And

$$
\begin{aligned}
\frac{\partial \Pi}{\partial E} & =-\frac{d r_{1}}{d E}\left(L-D_{0}\left(r_{0}\right)-E\right)+r_{1}(E) \\
& =r_{1}(E)\left(1-\eta_{E}^{r_{1}} \frac{D_{1}}{E}\right)>0
\end{aligned}
$$

Where $\eta_{E}^{r_{1}}=\frac{d r_{1}}{d E} \frac{E}{r_{1}}<0$ is the elasticity of $r_{1}$ w.r.t. E. The absolute value of this elasticity can be considered a measure of the (degree) of market discipline. If it equals zero there is no market discipline and the greater it is the greater is the degree of market discipline. The first order condition can be written as an equality of the marginal revenue and marginal cost of equity:

$$
\frac{d P}{d E} \Pi+P \frac{\partial \Pi}{\partial E}+\lambda=\frac{d k}{d E}
$$


The marginal revenue (LHS of (6)) has three components: the direct effect of $\mathrm{E}$ on the probability of survival $P$; the indirect effect, via market discipline, $P \frac{\partial \Pi}{\partial E}$ is larger as the market discipline $\left|\eta_{E}^{r_{1}}\right|$ is larger; the third factor $\lambda$ reflects the saving in insurance premium due to a decrease in deposits as E increases, where in the current model total assets are fixed. Moreover the effect of $\lambda$ on the marginal revenue of $E$ is smaller if the deposit insurance premium is risk adjusted. Thus, assuming that risk adjusted $\lambda$ is a decreasing function of E, we modify (6) to be:

$\frac{d P}{d E} \Pi+P \frac{\partial \Pi}{\partial E}+\lambda\left(1+\frac{d \lambda}{d E} \frac{E}{\lambda}\right)=\frac{d k}{d E}$

Where the last term on the LHS of (6a) is the risk adjusted insurance premium where by definition $\frac{d \lambda}{d E}<0$ and also the elasticity $\frac{d \lambda}{d E} \frac{E}{\lambda}<0$

Thus adjusting the insurance premium is equivalent to reducing $\lambda$ since $\lambda\left(1+\frac{d \lambda}{d E} \frac{E}{\lambda}\right)<\lambda$. The result will be equity capital $E$ will that is smaller than in the case of a flat premium, this can be seen in Figure 1: $\mathrm{E}^{* *}<\mathrm{E}^{*}$ because of the negative effect of $\mathrm{E}$ on the insurance premium, where $\mathrm{E}^{*}$ is optimal equity when the insurance premium is flat (constant) following (6), and $\mathrm{E}^{* *}$ is optimal equity when the insurance premium is risk adjusted following (6a).

Insert FIGURE 1

We now focus on the first order condition w.r.t. $\mathrm{r}_{0}$

$$
\begin{aligned}
& \frac{\partial N I}{\partial r_{0}}=P \frac{\partial \Pi}{\partial r_{0}}=-P\left[D_{0}-\frac{d D_{0}}{d r_{0}}\left(r_{1}(E)-r_{0}\right)\right]=0 \\
& \text { or } \\
& D_{0}+\frac{d D_{0}}{d r_{0}} r_{0}=\frac{d D_{0}}{d r_{0}} r_{1}(E)
\end{aligned}
$$


The LHS of (7) is the marginal cost of the interest rate on insured deposits: the increase in the cost of insured deposits $r_{0} D_{0}$ as $r_{0}$ increases, and the RHS of (7) is the marginal revenue: the decrease in cost of the uninsured deposits. An internal solution requires that in equilibrium $r_{1}>r_{0}$, otherwise the bank would raise no insured deposits.

Rewriting the condition in terms of the elasticity of the supply function of insured deposits $\mathrm{D}_{0}$ w.r.t $\mathrm{r}_{0}, \eta_{r_{0}}^{D_{0}}=\frac{d D_{0}}{d r_{0}} \frac{r_{0}}{D_{0}}$,we obtain

$$
\begin{aligned}
& \frac{\partial N I}{\partial r_{0}}=-P D_{0}\left[1-\eta_{r_{0}}^{D_{0}}\left(\frac{r_{1}(E)}{r_{0}}-1\right)\right]=0 \\
& \text { or } \\
& \frac{r_{1}}{r_{0}}=1+\frac{1}{\eta_{r_{0}}^{D_{0}}}
\end{aligned}
$$

As the market for insured deposits becomes more competitive the supply elasticity increases and the risk premium (ratio of $r_{1}$ to $r_{0}$ ) will decline. The implication is that with the recent deregulation in US banking, that removed restrictions on banking activities, it may expected that the supply curve of insured deposits will become more elastic (as the effective size of the market increases from a local to a national market) and the rate differential $\left(\mathrm{r}_{1}-\mathrm{r}_{0}\right)$ will decline. Further analysis of this point is presented in the next section.

We assume that the second derivatives:

$\frac{d^{2} k}{d E^{2}}, \frac{d^{2} P}{d E^{2}}, \frac{d^{2} D_{0}}{d r_{0}^{2}}, \frac{d^{2} r_{1}}{d E^{2}}$ have the proper signs so that the second order conditions hold globally i.e.:

$\frac{\partial^{2} N I}{\partial E^{2}}<0, \frac{\partial^{2} N I}{\partial r_{0}^{2}}<0 \quad$ and $\quad \frac{\partial^{2} N I}{\partial E^{2}} \frac{\partial^{2} N I}{\partial r_{0}^{2}}>\left(\frac{\partial^{2} N I}{\partial E d r_{0}}\right)^{2}$

In Figure 2 the two lines EE' and rr' illustrate the FOC (6) and (7) respectively. The optimal solutions of $\mathrm{E}$ and $\mathrm{r}_{0}$ are presented as the intersection of the two lines. 


\section{Insert FIGURE 2}

Each of the lines is a relationship between $\mathrm{E}$ and $\mathrm{r}_{0}$ as derived from the relevant first order condition. The two lines have negative slopes and the EE' line is steeper than the rr' line, this follows from the sign of the cross derivatives and the second order conditions, see Appendix A. The relationships presented in Figure 2 will be used to trace the effects of changes in the parameters in the comparative statics analysis that follows.

\section{Comparative statics analysis}

We start with a comparative analysis of the impact of the parameters of the model on the decision variables $r_{0}$ and $\mathrm{E}$.

For a change in a generic parameter $\theta$ we differentiate the FOC (6) and (7) w.r.t. $\theta$ :

$\frac{\partial^{2} N I}{\partial r_{0}^{2}} \frac{d r_{0}}{d \theta}+\frac{\partial^{2} N I}{\partial r_{0} \partial E} \frac{d E}{d \theta}+\frac{\partial^{2} N I}{\partial r_{0} \partial \theta}=0$

And similarly

$\frac{\partial^{2} N I}{\partial E \partial r_{0}} \frac{d r_{0}}{d \theta}+\frac{\partial^{2} N I}{\partial E^{2}} \frac{d E}{d \theta}+\frac{\partial^{2} N I}{\partial E \partial \theta}=0$

The last terms on the LHS of (10) and (11) are the direct effects of $\theta$, while the other terms are the indirect effects through $\mathrm{E}$ and $\mathrm{r}_{0}$.

The solutions of equations (10) and (11) for the two unknowns $\frac{d r_{0}}{d \theta}$ and $\frac{d E}{d \theta}$, are the effects of a change in the parameter $\theta$ on $\mathrm{r}_{0}$ and $\mathrm{E}$ : 
$\frac{d r_{0}}{d \theta}=\left(-\frac{\partial^{2} N I}{\partial r_{0} \partial \theta} \frac{\partial^{2} N I}{\partial E^{2}}+\frac{\partial^{2} N I}{\partial E \partial \theta} \frac{\partial^{2} N I}{\partial r_{0} \partial E}\right) /$

and

$\frac{d E}{d \theta}=\left(-\frac{\partial^{2} N I}{\partial r_{0}^{2}} \frac{\partial^{2} N I}{\partial E \partial \theta}+\frac{\partial^{2} N I}{\partial r_{0} \partial E} \frac{\partial^{2} N I}{\partial r_{0} \partial \theta}\right) / \Delta$

where by the second order conditions we have:

$$
\Delta=\frac{\partial^{2} N I}{\partial r_{0}^{2}} \frac{\partial^{2} N I}{\partial E^{2}}-\left(\frac{\partial^{2} N I}{\partial r_{0} \partial E}\right)^{2}>0
$$

In the following analysis we consider the effects of changes in six parameters on $\mathrm{E}$ and $r_{0}$. For each we first attempt to motivate the change by providing a relevant historic background. Secondly we obtain the signs of $\frac{d r_{0}}{d \theta}$ and $\frac{d E}{d \theta}$ by substituting the relevant terms in (12). Finally we illustrate the results graphically by shifts of the EE' and rr' lines in Figure2, these are presented in Figure 3. The results are summarized in Table 1.

We first analyze two cases involving the deposit insurance premium:

1. Insurance premium $\lambda$ increases and

2. Insurance premium is adjusted for risk $\lambda(\mathrm{E})$ see (6a); interestingly this is equivalent to reducing $\lambda$ since $\lambda\left(1+\eta_{E}^{\lambda}\right)<\lambda$ where $\eta_{E}^{\lambda}=\frac{\partial \lambda}{\partial E} \frac{E}{\lambda}<0$.

The 1980's U.S. dual crises of banking and savings and loans associations (S\&L) resulted in a dramatic increase in failures of institutions to levels more than ten times greater than in the period 1934-1980. The crisis in banking is attributed to increased competition due to financial innovation and deregulation, while the savings and loans 
crisis was caused mainly by interest rate risk (mismatch of long term mortgages and short term deposits). The crises were aggravated by moral hazard incentive provided by deposit insurance which increased risk taking by the financial intermediaries, and by regulatory forbearance that allowed failing institutions to continue to operate ("zombie" institutions). Increased losses of the FDIC (BIF) and the need to address problems of moral hazard created by deposit insurance resulted in the Federal Deposit Insurance Corporation Improvement Act of 1991 (FDICIA). Major provisions of the act recapitalized the FDIC, mandated prompt corrective action and ordered the creation of risk-based deposit insurance premiums. See FDIC (2002).

For an increase in $\lambda$, substituting $\theta=\lambda$, in (12)

$\frac{\partial^{2} N I}{\partial E \partial \lambda}=1$ and $\frac{\partial^{2} N I}{\partial r_{0} \partial \lambda}=0$

Yielding as expected a decline in $\mathrm{r}_{0}$ (and $\mathrm{D}_{0}$ ) and an increase in $\mathrm{E}$

$$
\begin{aligned}
& \frac{d r_{0}}{d \lambda}=\frac{\partial^{2} N I}{\partial r_{0} \partial E} / \Delta<0 \\
& \text { and } \\
& \frac{d E}{d \lambda}=-\frac{\partial^{2} N I}{\partial r_{0}^{2}} / \Delta>0
\end{aligned}
$$

Since $\lambda$ does not appear in (7), the rr' line is invariant under a change of $\lambda$. In order to retain the equality of (6) [or (6a)] following an increase [decrease] of $\lambda$ we have to decrease [increase] the term $\frac{d P}{d E} \Pi+P \frac{d \Pi}{d E}$ in this equation. In equilibrium, where $\frac{\partial \Pi}{\partial r_{0}}=0$,

The partial derivative of this term w.r.t. $\mathrm{r}_{0}$ is negative: $\frac{d P}{d E} \frac{\partial \Pi}{\partial r_{0}}+P \frac{\partial^{2} \Pi}{\partial E \partial r_{0}}<0$. Therefore for every $\mathrm{E}$ we have to increase [decrease] $\mathrm{r}_{0}$ which means an upward 
[downward] shift of the EE' line. Thus an increase in the insurance premium results in an increase [decrease] in the optimal value of $\mathrm{E}$ and a decline [increase] of the interest rate on insured deposits $\mathrm{r}_{0}$ (and also decline of $\mathrm{D}_{0}$ ), this is consistent with the inequalities of (13). See Figure 3a [3b].

The policy implication of this result is that if the deposit insurance premium is adjusted for risk to reduce moral hazard, the supervisory authorities have either to increase the capital requirement or raise the insurance premium schedule, to prevent a reduction in equity capital by the banks. For a discussion of the socially optimal deposit insurance premium see Landskroner and Paroush (1994).

3. The insured deposits market becomes more competitive Until recently competition in banking in the U.S. has been restricted by legislation that separated commercial banking from investment banking (Glass Steagall Act of 1933), and limited state branching and interstate banking. Recent legislation removed these restrictions and that is expected to increase competition in banking. The RiegleNeal Interstate Banking and Branching Efficiency Act of 1994 permits bank holding companies to acquire banks in any state and allows interstate mergers, also most states reduced or eliminated branching restrictions. The Gramm-Leach Bliley Act of 1999 repealed the Glass Steagall Act, allowing commercial banks to engage in insurance and investment banking (securities). In our model increased competition is reflected by an increase in the supply elasticity of insured deposits. This was the market most restricted by previous regulation.

For $\theta=\eta_{r_{0}}^{D_{0}}, \frac{\partial^{2} N I}{\partial E \partial \eta_{r_{0}}^{D_{0}}}=0$ and $\frac{\partial^{2} N I}{\partial r_{0} \partial \eta_{r_{0}}^{D_{0}}}>0$, substitute in (12) to obtain 


$$
\frac{d r_{0}}{d \eta_{r_{0}}^{D_{0}}}=-\frac{\partial^{2} N I}{\partial r_{0} \partial \eta_{r_{0}}^{D_{0}}} \frac{\partial^{2} N I}{\partial E^{2}} /{ }_{\Delta}>0
$$

and

$$
\frac{d E}{d \eta_{r_{0}}^{D_{0}}}=\frac{\partial^{2} N I}{\partial r_{0} \partial E} \frac{\partial^{2} N I}{\partial r_{0} \partial \eta_{r_{0}}^{D_{0}}} /{ }_{\Delta}<0
$$

Note that since $\eta_{r_{0}}^{D_{0}}$ does not appear in (6), the EE' line in Figure 2 is invariant under the change of $\eta_{r_{0}}^{D_{0}}$. In order to retain the equality of (8) we have to increase $\mathrm{r}_{0}$ for every value E, which means an upward shift of the rr' line and thus optimal E declines while optimal $r_{0}$ increases. These results are consistent with (14) and are illustrated in Figure3c. That is a less regulated and more competitive banking industry will result in higher interest rate paid on insured deposits, but lower equity capital which has implications for capital adequacy.

4. The degree of market discipline $-\eta_{E}^{r_{1}}$ increases:

The degree of market discipline can be considered a function of three factors: the level of coverage of deposit insurance (currently the limit is $\$ 100,000$ per account) provided by the FDIC that is inversely related to market discipline (sensitivity of $\mathrm{r}_{1}$ to risk), as this limit is reduced more depositors become uninsured (leave the safety net) and have an incentive to monitor the bank; level of competition in the uninsured deposit market (may be measured by $\mathrm{H}$ the Herfindahl-Hirschman index) which is positively related to market discipline, in our model $\mathrm{H}=0$ since we assume perfect competition in this market; the third factor is the expected recovery rate in case of bank failure, the higher the rate the smaller will be the degree of market discipline. 
The elasticity $\eta_{E}^{r_{1}}$ does not appear in (7) and thus $\frac{\partial N I}{\partial r_{0} \partial \eta_{E}^{r_{1}}}=0$ and the rr' line in Figure 2 is invariant under such a change. On the other hand we have from (3) and (5) $\frac{\partial N I}{\partial E \partial \eta_{E}^{r_{1}}}>0$ thus obtaining:

$$
\begin{aligned}
& \frac{d r_{0}}{d \eta_{E}^{r_{1}}}=\frac{\partial^{2} N I}{\partial E \partial \eta_{E}^{r_{1}}} \frac{\partial^{2} N I}{\partial r_{0} \partial E} /_{\Delta}<0 \\
& \text { and } \\
& \frac{d E}{d \eta_{E}^{r_{1}}}=-\frac{\partial^{2} N I}{\partial r_{0}^{2}} \frac{\partial^{2} N I}{\partial E \partial \eta_{E}^{r_{1}}} /_{\Delta}>0
\end{aligned}
$$

Note that since $\frac{\partial N I}{\partial E \partial \eta_{E}^{r_{1}}}>0$ we have to decrease $\frac{d P}{d E} \Pi+P \frac{d \Pi}{d E}$ in order to maintain the equality of (3). By the FOC we have $\frac{d \Pi}{d r_{0}}=0$ and $\frac{\partial^{2} \Pi}{\partial E \partial r_{0}}<0$, thus to retain the equilibrium we have to increase $r_{0}$ for every E. This means an upward shift in the EE' line, which results in an increase in $\mathrm{E}$ and a decline in $\mathrm{r}_{0}$, and which is consistent with (15), see Figure3a. Thus as the sensitivity of $r_{1}$ to $E$ increases $r_{0}$ declines and $E$ increases.

5. The marginal cost of equity $\mathrm{k}$ increases (higher risk premium)

That is for $\theta=\frac{d k}{d E} \equiv k^{\prime}$ the marginal cost of equity, we obtain by differentiation of

(6) and (7): $\frac{\partial^{2} \Pi}{\partial E \partial k^{\prime}}=-1$ and $\frac{\partial^{2} \Pi}{\partial r_{0} \partial k^{\prime}}=0$

Substituting these equations in (12) yields: 
$\frac{d r_{0}}{d k^{\prime}}=-\frac{\partial^{2} \Pi}{\partial r_{0} \partial E} / \Delta>0$

and

$\frac{d E}{d k^{\prime}}=\frac{\partial^{2} \Pi}{\partial r_{0}^{2}} / \Delta<0$

An increase in the marginal cost of equity $\frac{d k}{d E}$ has a similar effect to a decrease in $\lambda$, see (3). Thus as EE' shifts down E will decline, as equity becomes more expensive $\mathrm{r}_{0}$ will be increased to attract additional deposits. See Figure 3b.

6. The probability of bank solvency increases

The most important developments in banking in recent years have been: consolidation mainly through mergers and acquisitions; globalization and deregulation, which removed barriers in banking. These developments affect the risk exposure of banks mainly credit risk and market risks and thus also impact the insolvency risk of banks. See Paroush (1995) on the effects of mergers and acquisitions on the safety and soundness of the banking system, Saunders and Cornnet (2003) for a discussion of the risks faced by financial intermediaries. A change in systemic risk may also be due to changes in the macro economic environment such as recession, inflation or shocks to the economy (oil crisis). See Landskroner and Ruthenberg (1985) on the effect of inflation risk on bank management. Another exogenous change of $\mathrm{P}$ may be reflected in a change in the rating of the bank by a rating agency. See Billet, et al. (1998).

An exogenous change in $\mathrm{P}$ can be considered to be a result of a change in the factors that affect P other than E. P has no effect on the FOC (7) and therefore does not affect the rr' line in Figure 2, following $\frac{\partial^{2} N I}{\partial r_{0} \partial P}=0$. We assume that an exogenous change in risk affects $\mathrm{P}$ but not the slope $\mathrm{dP} / \mathrm{dE}$. Since $\mathrm{d} \Pi / \mathrm{dE}>0$ at equilibrium, the effect of an increase in the P on FOC (6) is similar to an increase in $\lambda$ i.e. $\frac{\partial^{2} N I}{\partial E \partial P}>0$ yielding: 


$$
\frac{d r_{0}}{d P}=\frac{\partial^{2} N I}{\partial E \partial P} \frac{\partial^{2} N I}{\partial r_{0} \partial E} / \Delta<0
$$

and

$\frac{d E}{d P}=-\frac{\partial^{2} N I}{d r_{0}^{2}} \frac{\partial^{2} N I}{\partial E \partial P} / \Delta>0$

In order to retain equilibrium in (3) we have to reduce $\frac{\partial P}{\partial E} \Pi+P \frac{\partial \Pi}{\partial E}$. Since WHY IS

$\frac{\partial \Pi}{\partial r_{0}}=0$ and $\frac{\partial^{2} \Pi}{\partial E \partial r_{0}}<0$ we have to increase $r_{0}$ for every $E$ this will result in an upward shift in the EE' line. That is a decrease in insolvency risk will cause a decline in the deposit rate $r_{0}$ and an increase in E. These changes are consistent with (17), see Figure 3a. An increase of the probability of bank insolvency (1-P) yields an inverse impact i.e. a decrease in $\mathrm{E}$ and increase of $\mathrm{r}_{0}$.

A decline in equity and an increase in the interest on insured deposits serve as a signal of an increase in the bank's risk all other things being equal. Thus an exogenous increase in risk (say oil prices shock) reduces $\mathrm{P}$, will result in holding less equity and consequently a higher interest rate on insured deposits.

Note since $r_{1}$ is inversely related to $E$, the two interest rates move in the same direction as risk changes. In our extended model (Section III) $\mathrm{r}_{\mathrm{L}}$ becomes a decision variable, risk will also be positively related to $\mathrm{r}_{\mathrm{L}}$. Thus, the three interest rates will be positively correlated.

Table 1 summarizes the results of our comparative statics analysis. 
Table 1: Effects of parameter changes on optimal values of variables

\begin{tabular}{|l|c|c|c|c|}
\hline Event/ Variable & $\mathrm{E}$ & $\mathrm{r}_{0}$ & $\mathrm{D}_{0}$ & $\begin{array}{c}\mathrm{D}_{1} \text { and } \\
\mathrm{D}_{1} /\left(\mathrm{D}_{1}+\mathrm{D}_{0}\right)\end{array}$ \\
\hline $1: \lambda \uparrow$ & + & - & - & + \\
\hline $2: \lambda$ risk adjusted & - & + & + & - \\
\hline 3:Competition $\uparrow$ & - & + & + & + \\
\hline 4:Mkt.Discipline $\uparrow$ & + & - & + & - \\
\hline 5: Equity cost $\uparrow$ & - & + & - & + \\
\hline 6: bank risk $\downarrow$ & + & - & & + \\
\hline
\end{tabular}

The upward shift in the EE' line in figure 3a, causing an increase in $\mathrm{E}$ and a decline in $\mathrm{r}_{0}$, reflects the result of event: 1,4 and 6

The downward shift in the EE' line in figure $3 \mathrm{~b}$, causing a decline in $\mathrm{E}$ and a rise in $\mathrm{r}_{0}$, reflects the result of event: 2 and 5.The upward shift in the rr' line in figure 3c, causing a decline in $\mathrm{E}$ and a rise in $\mathrm{r}_{0}$, reflects the result of event: 3 .

\section{Insert Figure 3}

We have obtained o far the impact of several parameters on $\mathrm{E}$ and $\mathrm{r}_{0}$ (and therefore also on $\mathrm{D}_{0}$ ). We now obtain the effects of the parameters on the optimal quantities of deposits: $\mathrm{D}_{1}$ and $\mathrm{D}_{1} /\left(\mathrm{D}_{0}+\mathrm{D}_{1}\right)$. In order to do that we need the results of two propositions, which are formulated and proven in Appendix B. A compact summary of Proposition 2 and Corollary 3 of Proposition 1 is given in the following theorem:

Theorem: If the degree of market discipline is sufficiently large then the effect of a change in any parameter on $D_{1}$ and on $D_{1} /\left(D_{0}+D_{1}\right)$ is opposite to its effect on $D_{0}$. In particular, an exogenous increase in the bank's insolvency risk will result in a shift from uninsured deposits to insured deposits. The results of the last column of Table 1 are thus obtained; in all cases where insured deposits decline (increase) as a result of a 
decline (increase) in their own interest rate, the uninsured deposits increase (decline) in absolute and relative terms.

We now refer to the empirical literature where the findings of the studies can serve as statistical test of our theoretical hypotheses derived from the comparative statics analysis. These findings validate our model as a useful framework for analyzing and explaining the phenomena of market discipline and its effects.

Recently studies have focused on the price and quantity effects of market discipline using bank debt yields and quantities of insured vs. uninsured deposits data, most have found a significant market effect. Specifically as predicted by our model subordinated debt (i.e. uninsured liability) spreads were found in the U.S. and Europe to reflect bank risk. Studies that tested the effects of market discipline on interest rates are cited at the end of the next section.

A number of empirical studies examine the quantity effects of exogenous changes in risk, probability of insolvency, on the behavior of insured vs. uninsured deposits. Billet et al. (1998) examine the relationship between changes in bank credit risk and the use of insured deposits, they find that downgrading of banks debt by Moody's (increase in probability of bank default) increases their use of insured deposits, symmetrically banks reduce their use of insured deposits following upgrades. This consistent with the results presented in Table1 (case 6). Park and Peristani (1998) empirical findings suggest a price and quantity effect which is more pronounced: riskier thrifts not only paid higher interest rates on uninsured deposits but also attracted a smaller quantity of uninsured deposits. Goldberg and Hudgins (2002) find that failed thrifts had declining proportions of uninsured deposits to total deposits and a lower proportion of uninsured deposits to total deposits prior to failure than solvent institutions, the empirical results indicate that uninsured deposits will have incentives to monitor and discipline thrifts risk exposure and that reducing deposit insurance limits will increase market discipline. These findings are consistent with our analytical results as presented in the comparative statics analysis. The empirical findings on the price effects: effects on interest rates on insured vs. uninsured deposits will be discussed in the next section. 


\section{Asset and Liability Management Model}

We now turn to the analysis where the bank is managing both its assets and liabilities (ALM), thus relaxing the assumption that total assets are fixed. Assume that the bank has two types of assets: risky loans (say commercial and industrial loans, real estate loans), which are assumed to be equally risky, and riskless securities (U.S. government and agencies). We assume that the bank possesses some monopolistic power in the loan market so that the demand for risky loans $\mathrm{L}$ is negatively related to the interest rate on these loans $r_{L}$. The quantity of the riskless securities $S$, is assumed fixed for sake of simplicity. The operating costs associated with the size of the bank are assumed to be a function of total assets, $C(L+S)^{10}$. The relevant measure of the risk faced by the bank is now the risk adjusted equity capital ratio e=E/L. In terms of the 1988 Basel Accord on capital adequacy we assume the risk weights of the risky loans equal one and that of the securities to be zero. In our model E is a market or economic value and not an accounting value. The risk adjusted equity capital ratio reflects the (inverse of) risk of default of the assets and the financial leverage of the bank. Thus as the risk adjusted capital ratio increases the interest rate demanded by the uninsured depositors, $\mathrm{r}_{1}(\mathrm{e})$ declines.

The decision variables of the bank are now: e, $r_{0}$ and $r_{L}$ where $S$ is assumed fixed. The bank's objective function under the extended model can now be written as:

$$
\begin{aligned}
& N I=P(e)\left\{r_{s} S+r_{L} L\left(r_{L}\right)-\left[r_{0} D_{0}\left(r_{0}\right)+r_{1}(e)\left(S+L\left(r_{L}\right)-D_{0}\left(r_{0}\right)-e L\left(r_{L}\right)\right)\right]\right\} \\
& -\lambda\left(D_{0}\left(r_{0}\right)+\left(S+L\left(r_{L}\right)-D_{0}\left(r_{0}\right)-e L\left(r_{L}\right)\right)\right)-k(e L)-C(L+S)
\end{aligned}
$$

Rewriting (18):

$$
\begin{aligned}
& N I=P(e) \Pi-\lambda\left[S+(1-e) L\left(r_{L}\right)\right]-k(e L)-C(L+S) \\
& \text { where } \Pi=\left[r_{L}-r_{1}(e)(1-e)\right] L\left(r_{L}\right)+\left(r_{1}(e)-r_{0}\right) D_{0}\left(r_{0}\right)+r_{s} S
\end{aligned}
$$

where we have substituted the following budget constraint

$$
D_{1}=S+L\left(r_{L}\right)-D_{0}\left(r_{0}\right)-e L\left(r_{L}\right)=(1-e) L\left(r_{L}\right)-D_{0}\left(r_{0}\right)+S
$$

\footnotetext{
${ }^{10}$ Note that $\mathrm{C}(\mathrm{L}+\mathrm{S})$ may have a jump at $\mathrm{L}=\mathrm{E} / \alpha$ where $\alpha$ is the capital adequacy requirement imposed by the supervisory authority.
} 
Note that in order to have in internal solutions equilibrium we must have $r_{1}(e)>r_{0}$ otherwise no insured deposits will be raised; and $\mathrm{r}_{\mathrm{L}}>\mathrm{r}_{1}(\mathrm{e})(1-\mathrm{e})$ in order to have positive net income from loans.

The first order conditions follow. The FOC w.r.t the equity capital ratio e is

$$
\frac{d P}{d e} \Pi+P \frac{d \Pi}{d e}+\lambda L\left(r_{L}\right)-\frac{d k}{d e}=0
$$

where

$$
\begin{aligned}
\frac{d \Pi}{d e} & =-\frac{d r_{1}}{d e}\left[S+L\left(r_{L}\right)-D_{0}\left(r_{0}\right)-e L\left(r_{L}\right)\right]+r_{1}(e) L\left(r_{L}\right) \\
& =\frac{r_{1}(e)}{e}\left[\left(-\eta_{e}^{r_{1}}\right) D_{1}+e L\left(r_{L}\right)\right]>0
\end{aligned}
$$

Note $\frac{d \Pi}{d e}>0$ since the market discipline $\eta_{e}^{r_{1}}=\frac{d r_{1}}{d e} \frac{e}{r_{1}}<0$. Recall the negative relationship between the risk adjusted capital ratio and the interest rate paid on the uninsured deposits.

The FOC w.r.t. $r_{0}$ is the same as in (7) and also the result of (8) about the effect of the elasticity of supply of uninsured deposits on the spread between the uninsured and insured deposit rates holds, where e replaces E.

The FOC w.r.t. $\mathrm{r}_{\mathrm{L}}$ :

$$
P L+\frac{d L}{d r_{L}}\left[\operatorname{Pr}_{L}-\operatorname{Pr}_{1}(1-e)-\lambda(1-e)-\frac{d k}{d L}-\frac{d C}{d L}\right]=0
$$

Equation (22) can also be written as an equality of the marginal revenue and marginal cost of $\mathrm{r}_{\mathrm{L}}$ :

$$
\operatorname{Pr}_{L}\left(1-\frac{1}{\eta_{r_{L}}^{L}}\right)=(1-e)\left(\operatorname{Pr}_{1}+\lambda\right)+\frac{d C}{d L}+\frac{d k}{d L}
$$

Where $\eta_{r_{L}}^{L}<-1$ is the elasticity of the demand for loans L w.r.t. $r_{L}$. The LHS of (23) is the expected marginal revenue and on the RHS we have three components of marginal 
costs: the expected cost of uninsured deposits and deposit insurance premium adjusted by (1-e) which reflects the ratio of loans financed by deposits, the marginal operating costs and finally the increasing equity costs. Note that $\mathrm{L}$ increase where $\mathrm{e}=\mathrm{E} / \mathrm{L}$ is constant.

\section{Comparative Statics Analysis}

A complete comparative statics analysis is quite cumbersome and therefore will not be presented here. We have however derived explicit results w.r.t the parameters $\lambda$ and $\mathrm{P}$ that are of particular interest. Appendix C presents the formal derivation of the results.

Specifically consider the impact of a change in the deposit insurance premium, i.e. $\theta=\lambda$, we obtain

$\frac{\partial^{2} N I}{\partial e \partial \lambda}=L>0$ by (20), also

$\frac{\partial^{2} N I}{\partial r_{0} \partial \lambda}=0$ by (7), and

$\left.\frac{\partial^{2} N I}{\partial r_{L} \partial \lambda}=-\frac{d L}{d r_{L}}(1-e)\right)>0$ by (22)

Use the sign to find from (C2b) that

$\operatorname{sign} \frac{d e}{d \lambda} \neq \operatorname{sign} \frac{d r_{0}}{d \lambda}$

and from (C2c) we get

sign $\frac{d e}{d \lambda}$ and sign $\frac{d r_{L}}{d \lambda}$ can not be both negative

Substitute $\frac{d e}{d \lambda}=-\left(\frac{\partial^{2} N I}{\partial r_{0}^{2}} / \frac{\partial^{2} N I}{\partial r_{0} \partial e}\right) \frac{d r_{0}}{d \lambda}$ in (C2a) to obtain

$\left(\frac{-\frac{\partial^{2} N I}{\partial e^{2}} \frac{\partial^{2} N I}{\partial r_{0}^{2}}}{\frac{\partial^{2} N I}{\partial r_{0} \partial e}}+\frac{\partial^{2} N I}{\partial r_{0} \partial e}\right) \frac{d r_{0}}{d \lambda}+\frac{\partial^{2} N I}{\partial e \partial r_{L}} \frac{d r_{L}}{d \lambda}+L=0$ 
Since $\frac{\partial^{2} N I}{\partial r_{0} \partial e}<0$ and $\frac{\partial^{2} N I}{\partial e^{2}} \frac{\partial^{2} N I}{\partial r_{0}{ }^{2}}>\left(\frac{\partial^{2} N I}{\partial r_{0} \partial e}\right)^{2}$ by SOC, the coefficient of $\frac{d r_{0}}{d \lambda}$ is negative but $\frac{\partial^{2} N I}{\partial e \partial r_{L}}<0$ then $\frac{d r_{0}}{d \lambda}$ and $\frac{d r_{L}}{d \lambda}$ cannot both be negative. Also by substitution of $\frac{d e}{d \lambda}$ in (24b) we obtain

$\operatorname{sign} \frac{d r_{0}}{d \lambda} \leq \operatorname{sign} \frac{d r_{L}}{d \lambda}$

Thus if $\frac{d e}{d \lambda}>0 \Rightarrow \frac{d r_{0}}{d \lambda}<0$

And if $\frac{d e}{d \lambda}<0 \Rightarrow \frac{d r_{0}}{d \lambda}>0$, and also $\frac{d r_{L}}{d \lambda}>0$

It is plausible that an increase in the deposit insurance premium will increase equity financing or reduce risk of assets.

Thus an increase in $\lambda$ will increase e, reduce $r_{0}$ and $r_{L}$ and reuce the quantity of both deposits.

Now let us consider the probability $\mathrm{P}$ as parameter ((1-P) is probability of insolvency of bank): $\theta=P$, and find out:

$$
\begin{aligned}
& \frac{\partial^{2} N I}{\partial e \partial P}>0 \text { by (20) } \\
& \begin{aligned}
\frac{\partial^{2} N I}{\partial r_{0} \partial P} & =0 \text { by (7), and since }-\frac{d r_{L}}{d L} \frac{L}{r_{L}}>0 \text { in equilibrium we obtain: } \\
\frac{\partial^{2} N I}{\partial r_{L} \partial P} & =L+\frac{d L}{d r_{L}} r_{L}-\frac{d L}{d r_{L}} r_{1}(1-e) \\
& =L\left[1+\frac{d L}{d r_{L}} \frac{r_{L}}{L}\left(1-\frac{r_{1}(1-e)}{r_{L}}\right)\right]>0
\end{aligned}
\end{aligned}
$$

Thus the effect of $\mathrm{P}$ will be exactly as that of $\lambda$. For instance, as before, an increase in risk will reduce e, it will also increase $\mathrm{r}_{0}, \mathrm{r}_{\mathrm{L}}$ and also $\mathrm{D}_{0}$, and by the budget constraint it will reduce $\mathrm{D}_{1}$ and $\mathrm{D}_{1} /\left(\mathrm{D}_{0}+\mathrm{D}_{1}\right)$. 
Two results are obtained from the analysis. First, the directions of the effects of $\lambda$ and $P$ on the optimal values of e and $r_{0}$ under the extended model are identical to those under the restricted model (w.r.t. $E$ and $\mathrm{r}_{0}$ ), to wit de/d $\lambda>0$, de/dP $>0, \mathrm{dr}_{0} / \mathrm{d} \lambda<0$ and $\mathrm{dr}_{0} / \mathrm{dP}<0$ which is not surprising. Second a change in $\lambda$ and $P$ has the same effect on $r_{L}$ and $r_{0}$ and thus a positive relationship between $r_{L}$ and $r_{0}$ is obtained. Such a relationship is compatible with empirical findings. In addition (24c) shows that the impact of $\lambda$ and $\mathrm{P}$ on the spread $r_{L}-r_{0}$ is most likely to be positive. The findings here, as in the previous model, are that risk affects similarly $r_{1}$ and $r_{0}$.

A group of studies tested the effects of market discipline on interest rates (price effect). Subordinated debt spreads were found in the U.S. to be associated with bank risk. In an empirical analysis Evanoff and Wall (2001) compare various capital ratios and subordinated debt spreads as measures of risk and in predicting bank conditions, their results suggest that sub-debt yield spreads perform better than the best capital ratios. The authors conclude that the spreads can be used as "prompt corrective action” trigger. The time-series findings of Hancock and Kwast (2001) indicate that subordinated debt spreads of liquid bonds traded in a robust bond market can be used as measures of default risk, their results support the use of subordinated debt spreads in supervisory monitoring. Morgan and Stiroh (2001) investigate the relationship between bond spreads and the risk of the assets held by the bank, their results show that bond spreads reflect the overall mix of bank assets, they conclude that a shift of a bank to riskier activities will result in a higher spread that the bank will have to pay. ${ }^{11}$ Similar results are obtained also for other countries, Sironi (2002) investigated empirically the spreads of subordinated notes and debentures of major US banks and European banks, she finds a significant spread/rating relationship for European banks' bonds which is similar to U.S. banks; Peria and Schmukler (2001) found that during the 1980s and 1990s depositors in Argentina, Chile and Mexico disciplined banks by withdrawing deposits and requiring higher interest rates.

\footnotetext{
${ }^{11}$ Saunders (2001) criticizes the use of bond spread yields as they reflect not only default probability but also recovery rates and advocates the use of the more liquid equity market data rather than debt market data.
} 


\section{Main Results and Concluding Remarks}

This paper focuses on market discipline that is defined as the "direct effect" of the risk of the bank's assets and its capital structure on the cost of its funds. We suggest a definition as well as the measurement of the "degree of market discipline" as the sensitivity (elasticity) of the cost of uninsured deposits with respect to the capital structure adjusted for the risk of the bank's assets. It turns out that the "degree of market discipline” plays an important role in the management of banks. Within a stylized model of the optimal behavior of a bank we incorporates the characteristics of the regulatory structure and market discipline. Government regulation is introduced via deposit insurance provided to some of the depositors. We examine and derive the effects of several parameters on the optimal behavior of the bank, and relate them to recent developments in US banking. We have considered the effect of changes deposit insurance premium and risk adjusted premium, degree of market discipline, degree of competition in the financial sector, cost of equity and risk as reflected by the probability of insolvency of the bank. An increase in the insurance premium, increase in market discipline and a decrease in risk (increase in probability of solvency) will result in a greater amount of equity of the bank and a lower rate paid on insured deposits. On the other hand an increase in the cost of equity and increase in competition in the insured deposits market, will cause a decline in equity financing and increase in the rate paid on insured deposits.

We also derive the effect of the parameters on the quantities of deposits and their composition. An increase in the risk of the bank, an introduction of risk adjusted insurance premium and an increase competition in the insured deposits market will cause a reduction in the relative share of uninsured deposits (and increase of insured deposits) of the bank. An increase in the insurance premium (charged on all deposits) and in market discipline will result in an increase in the optimal relative share of uninsured deposits.

The main results (effects of the parameters) obtained under the constrained model where the bank manages only its liabilities are still valid under the more general model where the bank manages its assets as well as its liabilities. In addition under the extended model most parameters have similar impacts on the loan interest rate $\mathrm{r}_{\mathrm{L}}$ and the deposit rate $\mathrm{r}_{0}$. 
In most cases the analytical results of the model are compatible with existing empirical findings and thus can serve as a theoretical framework for explaining bank management decisions and for analyzing the effects of market discipline.

\section{Appendix A}

The slopes of the two lines are:

$$
\left(\frac{d r_{0}}{d E}\right)_{\frac{\partial N I}{\partial r_{0}}=0}=-\frac{\frac{\partial^{2} N I}{\partial E \partial r_{0}}}{\frac{\partial^{2} N I}{\partial r_{0}^{2}}} \quad\left(\frac{d r_{0}}{d E}\right)_{\frac{\partial N I}{\partial E}=0}=-\frac{\frac{\partial^{2} N I}{\partial E^{2}}}{\frac{\partial^{2} N I}{\partial E \partial r_{0}}}
$$

And thus the sign of the slopes of the lines is determined by the sign of the cross derivative

$\frac{\partial^{2} N I}{\partial E \partial r_{0}}=\frac{d D_{0}}{d r_{0}} \frac{d r_{1}}{d E}<0$

Therefore the two lines have negative slopes.

The difference between the two slopes is:

$$
\begin{aligned}
& \left(\frac{d r_{0}}{d E}\right)_{\frac{\partial N I}{\partial r_{0}}=0}-\left(\frac{d r_{0}}{d E}\right)_{\frac{\partial N I}{\partial E}=0}=-\frac{\frac{\partial^{2} N I}{\partial E \partial r_{0}}}{\frac{\partial^{2} N I}{\partial r_{0}^{2}}}+\frac{\frac{\partial^{2} N I}{\partial E^{2}}}{\frac{\partial^{2} N I}{\partial E \partial r_{0}}} \\
& =\frac{\frac{\partial^{2} N I}{\partial E^{2}} \frac{\partial^{2} N I}{\partial r_{0}^{2}}-\left(\frac{\partial^{2} N I}{\partial E \partial r_{0}}\right)^{2}}{\frac{\partial^{2} N I}{\partial r_{0}^{2}} \frac{\partial^{2} N I}{\partial E \partial r_{0}}}>0
\end{aligned}
$$

In (A2) the inequality is due to the positive sign of the numerator (by SOC (9)), and the product of the two negative terms in the denominator.

Thus the EE' line is steeper than the rr' line. 


\section{Appendix B}

Proposition $1: \mathrm{S}<\mathrm{R}$ is a necessary and sufficient condition for $\operatorname{sign} \frac{d D_{1}}{d \theta}=\operatorname{sign} \frac{d D_{0}}{d \theta}$ where $S=\frac{d D_{0}}{d r_{0}}$ and $R=\left|\frac{d E}{d \theta}\right| /\left|\frac{d r_{0}}{d \theta}\right|$

Proof : Since L is assumed constant, the budget constraint yields:

$\frac{d E}{d \theta}+\frac{d D_{0}}{d \theta}+\frac{d D_{1}}{d \theta}=0$

But

$\frac{d D_{0}}{d \theta}=\frac{d D_{0}}{d r_{0}} \frac{d r_{0}}{d \theta}=S \frac{d r_{0}}{d \theta}$ so that

$\frac{d D_{1}}{d \theta}=-\left(\frac{d E}{d \theta}+S \frac{d r_{0}}{d \theta}\right)$

Recall that the EE' line and the rr' line have negative slopes (See Appendix A). Therefore $\operatorname{sign} \frac{d E}{d \theta}=-\operatorname{sign} \frac{d r_{0}}{d \theta}$

Thus $\mathrm{S}<\mathrm{R}$ is a necessary and sufficient condition for

$\operatorname{sign}\left(\frac{d E}{d \theta}+S \frac{d r_{0}}{d \theta}\right)=\operatorname{sign} \frac{d E}{d \theta}$

Combine (B1) and (B2) to obtain

$\operatorname{sign} \frac{d D_{1}}{d \theta}=-\operatorname{sign} \frac{d E}{d \theta}=\operatorname{sign} \frac{d r_{0}}{d \theta}=\operatorname{sign} \frac{d D_{0}}{d \theta}$

Q.E.D.

Corollary 1: A sufficient condition for 
Sign $\frac{d D_{1}}{d \theta}=\operatorname{sign} \frac{d D_{0}}{d \theta}$ is $S<1$

Proof:

Recall that the EE' line is steeper than the rr' line(See Appendix A), this means that R>1 and if $\mathrm{S}<1$ we have also $\mathrm{S}<\mathrm{R}$.

Q.E.D.

Corollary 2: $\mathrm{S}>\mathrm{R}$ is a sufficient condition for

$$
\operatorname{sign} \frac{d D_{1}}{d \theta}=\operatorname{sign} d\left(\frac{D_{1}}{D_{0}+D_{1}}\right) / d \theta
$$

Proof: By Proposition1, S>R is a necessary and sufficient condition for

$$
\operatorname{sign} \frac{d D_{1}}{d \theta} \neq \operatorname{sign} \frac{d D_{0}}{d \theta}
$$

Note that we always have

$$
\operatorname{sign} \frac{d D_{0}}{d \theta}=\operatorname{sign} \frac{d r_{0}}{d \theta}=-\operatorname{sign} \frac{d E}{d \theta}=\operatorname{sign} \frac{d\left(D_{1}+D_{0}\right)}{d \theta}
$$

Combine (B4) and (B5) to obtain (B3) Q.E.D.

Corollary 3: If the degree of market discipline $\left|\eta_{E}^{r_{1}}\right|$ is sufficiently high then

$$
\operatorname{sign} \frac{d D_{0}}{d \theta} \neq \operatorname{sign} \frac{d D_{1}}{d \theta}
$$

Proof: by definition

$$
R=\frac{|d E / d \theta|}{\left|d r_{0} / d \theta\right|}=\frac{\left|d r_{1} / d \theta\right|}{\left|d r_{1} / d E\right|\left|d r_{0} / d \theta\right|}=\frac{\left|\eta_{\theta}^{r_{1}}\right| E / r_{0}}{\left|\eta_{E}^{r_{1}}\right| \eta_{\theta}^{r_{0}} \mid}
$$

The inequality $\mathrm{S}>\mathrm{R}$ is therefore equivalent to 
$\left|\eta_{E}^{r}\right|>\frac{\left|\eta_{\theta}^{r_{1}}\right| E / D_{0}}{\left|\eta_{\theta}^{r_{0}}\right| \eta_{r_{0}}^{D_{0}}}$

Q.E.D.

Proposition 2: The inequality

$\left|\eta_{E}^{r_{1}}\right|>\frac{\left|\eta_{\theta}^{r_{1}}\right|}{\left|\eta_{\theta}^{D_{1}}\right|} \frac{E}{L-E}$

is a necessary and sufficient condition for

$\operatorname{sign} \frac{d D_{1}}{d \theta}=\operatorname{sign} \frac{d\left(D_{1} /\left(D_{0}+D_{1}\right)\right)}{d \theta}$

Proof:

(B6) is equivalent to

$\left|\frac{d r_{1}}{d E}\right|>\frac{\left|d r_{1} / d \theta\right|}{\left|d D_{1} / d \theta\right|} \frac{D_{1}}{D_{0}+D_{1}}$

which is in turn equivalent to

$\left|\frac{d D_{1}}{d \theta}\right|>\left|\frac{d E}{d \theta}\right| \frac{D_{1}}{D_{0}+D_{1}}=\left|\frac{d\left(D_{0}+D_{1}\right)}{d \theta}\right| \frac{D_{1}}{D_{0}+D_{1}}$

But note that

$\frac{d\left(D_{1} /\left(D_{0}+D_{1}\right)\right)}{d \theta}=\frac{\frac{d D_{1}}{d \theta}\left(D_{0}+D_{1}\right)-\frac{d\left(D_{0}+D_{1}\right)}{d \theta} D_{1}}{\left(D_{0}+D_{1}\right)^{2}}=\frac{1}{D_{0}+D_{1}}\left[\frac{d D_{1}}{d \theta}-\frac{d\left(D_{0}+D_{1}\right)}{d \theta} \frac{D_{1}}{D_{0}+D_{1}}\right]$

Combine (B8) and (B9) to obtain (B7)

Q.E.D. 


\section{Appendix C}

A comparative statics analysis under the ALM model

For a change in a generic parameter $\theta$ we differentiate in turn the FOC (20), (7) and (22) to obtain the following system

$$
\begin{aligned}
& \frac{\partial^{2} N I}{\partial e^{2}} \frac{d e}{d \theta}+\frac{\partial^{2} N I}{\partial e \partial r_{0}} \frac{d r_{0}}{d \theta}+\frac{\partial^{2} N I}{\partial e \partial r_{L}} \frac{d r_{L}}{d \theta}+\frac{\partial^{2} N I}{\partial e \partial \theta}=0 \\
& \frac{\partial^{2} N I}{\partial r_{0} \partial e} \frac{d e}{d \theta}+\frac{\partial^{2} N I}{\partial r^{2}} \frac{d r_{0}}{d \theta}+\frac{\partial^{2} N I}{\partial r_{0} \partial r_{L}} \frac{d r_{L}}{d \theta}+\frac{\partial^{2} N I}{\partial r_{0} \partial \theta}=0 \\
& \frac{\partial^{2} N I}{\partial r_{L} \partial e} \frac{d e}{d \theta}+\frac{\partial^{2} N I}{\partial r_{L} \partial r_{0}} \frac{d r_{0}}{d \theta}+\frac{\partial^{2} N I}{\partial r_{L}^{2}} \frac{d r_{L}}{d \theta}+\frac{\partial^{2} N I}{\partial r_{L} \partial \theta}=0
\end{aligned}
$$

Since $\frac{\partial^{2} N I}{\partial r_{L} \partial r_{0}}=0$ by (22) or by (7) the system in (C1) is reduced to

$$
\begin{aligned}
\frac{\partial^{2} N I}{\partial e^{2}} \frac{d e}{d \theta}+\frac{\partial^{2} N I}{\partial e \partial r_{0}} \frac{d r_{0}}{d \theta}+\frac{\partial^{2} N I}{\partial e \partial r_{L}} \frac{d r_{L}}{d \theta}+\frac{\partial^{2} N I}{\partial e \partial \theta} & =0 \\
\frac{\partial^{2} N I}{\partial r_{0} \partial e} \frac{d e}{d \theta}+\frac{\partial^{2} N I}{\partial r_{0}^{2}} \frac{d r_{0}}{d \theta}+\frac{\partial^{2} N I}{\partial r_{0} \partial \theta} & =0 \\
\frac{\partial^{2} N I}{\partial r_{L} \partial e} \frac{d e}{d \theta}+\frac{\partial^{2} N I}{\partial r_{L}^{2}} \frac{d r_{L}}{d \theta}+\frac{\partial^{2} N I}{\partial r_{L} \partial \theta} & =0
\end{aligned}
$$

Note that by SOC $\frac{\partial N I^{2}}{\partial e^{2}}<0, \frac{\partial^{2} N I}{\partial r_{0}{ }^{2}}<0, \frac{\partial^{2} N I}{\partial r_{L}{ }^{2}}<0$ 
By (7) $\frac{\partial^{2} N I}{\partial r_{0} \partial e}=P \frac{d D_{0}}{d r_{0}} \frac{d r_{1}(e)}{d e}<0$

and by (22)

$$
\frac{\partial^{2} N I}{\partial r_{L} \partial e}=\frac{d L}{d r_{L}}\left[\operatorname{Pr}_{1}(e)+\lambda-P \frac{d r_{1}}{d e}(1-e)\right]=\frac{d L}{d r_{L}}\left[\lambda+\operatorname{Pr}_{1}(e)\left(1-\eta_{e}^{r_{1}}\right)\left(\frac{1-e}{e}\right)\right]<0
$$

\section{References}

Basel Committee on Banking Supervision, 2001, "The New Basel Capital Accord” Consultative Document, Bank for International Settlements, January.

Billet, M., Garfinkel, J., O’Neal, E., 1998, “The Cost of Market versus Regulatory Discipline in Banking” Journal of Financial Economics, 48, 333-358

Crocket, A., 2002, “Market Discipline and Financial Stability” Journal of Banking and Finance, 26, 977-987.

Demirguc-Kunt. A.and E. Detragiache, 1999, "Does Deposit Insurance Increase Banking System Stability? An Empirical Investigation” Working Paper No. 2247, World Bank.

Evanoff, D.D. and L.D. Wall, 2001, "Sub-debt Yield Spreads as Bank Risk Measures”, Journal of Financial Services Research, 20, 121-145.

FDIC, 2002, “Important Banking Legislation”, http://www.fdic.gov/regulations

Flannery, M.J., 1998, "Using Market Information in Prudential Bank Supervision: A Review of the U.S. Empirical Evidence”, Journal of Money, Credit, and Banking, 30, 273-305.

Flannery, M.J., 2001, "The Faces of Market Discipline” Journal of Financial Services Research, 20, 107-119.

Goldberg, L.G. and S.C. Hudgins, 2002, "Deposit Discipline and Changing Strategies for Regulating Thrift Institutions”, Journal of Financial Economics, 63, 263-274.

Hancock, D. and M.L. Kwast, 2001, "Using Subordinated Debt to Monitor Bank Holding Companies: Is it Feasible?” Journal of Financial Services Research, 20, 147-187.

Kwast, M.L., et. al , 1999, "Using Subordinated Debt as an Instrument of Market Discipline” Staff Study 172, Federal Reserve System, December. 
Landskroner, Y. and J. Paroush, 1994, "Deposit Insurance Pricing and Social Welfare," Journal of Banking and Finance, 18, 531-552.

Landskroner, Y. and D. Ruthenberg, 1985, "Optimal Bank Behavior Under Uncertain Inflation," Journal of Finance, 40, 1159-1171.

Morgan, D.P. and K.J. Stiroh, 2001, “Market Discipline of Banks: The Asset Test.” Journal of Financial Services Research, 20, 195-208

Park, S., Peristiani, S., 1998, "Market Discipline by Thrift Depositors.” Journal of Money Credit and Banking, 30, 347-364.

Paroush, J., 1988, "Domino effect and the Supervision of the Banking System” Journal of Finance, 43, 1207-1218.

Paroush, J., 1995, "The Effect of Mergers and Acquisitions on the Safety and Soundness of a Banking System.” The Review of Industrial Organization, 10, 53-67.

Peria, M.S.M. and S.L. Schmukler, 2001, "Do Depositors Punish Banks for Bad Behavior? Market Discipline, Deposit Insurance, and Banking Crises.” Journal of Finance, 56, 1029-1051.

Sironi, A.,2002, "Strengthening Bank Market Discipline and leveling the Playing Field: are the Two Compatible?” Journal of Banking and Finance, 26, 1065-1091.

Saunders, A., 2001, “Comments on Evanoff and Wall/ Hancok and Kwast” Journal of Financial Services Research, 20,189-194.

Saunders, A. and M.M. Cornett, 2003, "Financial Institutions Management”, $4^{\text {th }}$ ed. McGraw-Hill, Irwin, 4-20,138-153.

Sundaresan, S.M., 2001, "Supervisor and Market Analysis: What should Research be Seeking ?” Journal of Financial Services Research, 20, 275-280.

Williamson, John, 2001, “ Book Review of: Paul Krugman ed. Currency Crises. NBER Conference Report series. University of Chicago Press, 2000” Journal of Economic Literature, 39(3): 916-17. 
Figure 1:

Optimal Equity Capital and Deposit Insurance Premium

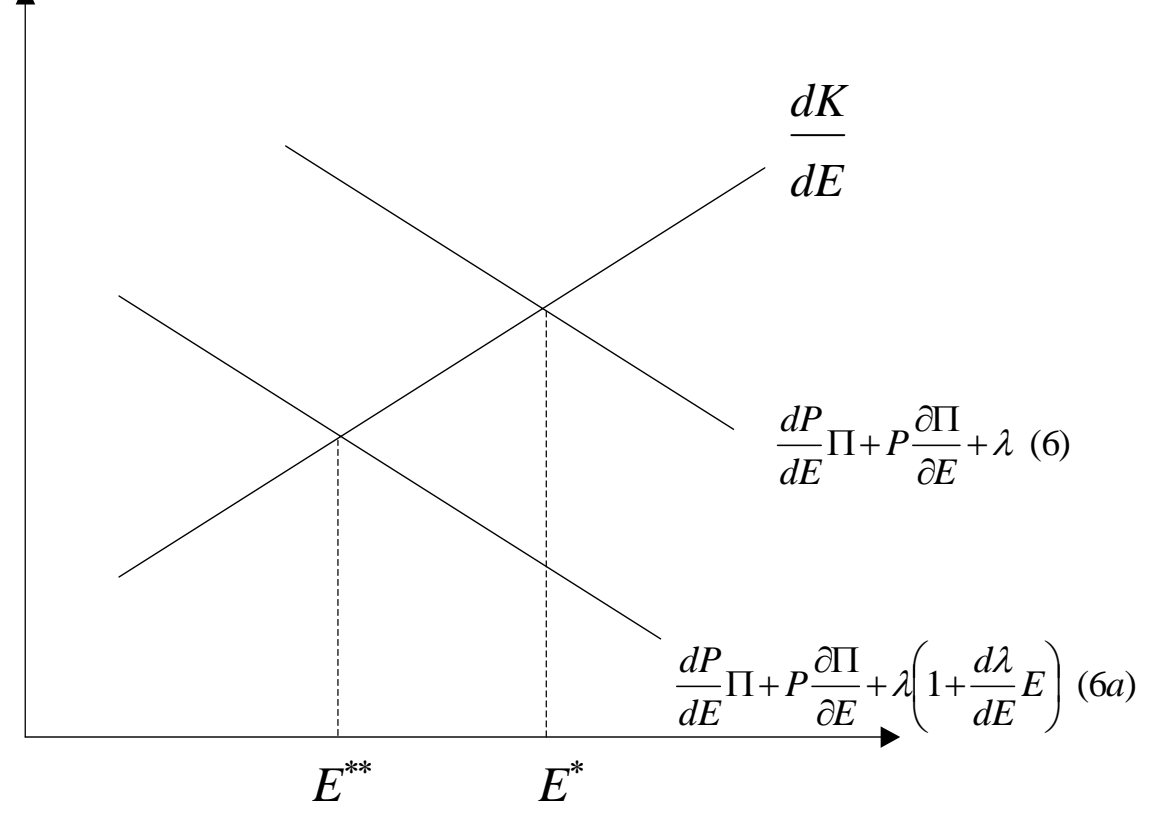

$\mathrm{E}^{*}$ is optimal equity capital if deposit insurance premium is constant

$\mathrm{E}^{* *}$ is optimal equity capital if deposit insurance premium is risk adjusted

Figure 2:

Optimal interest rate on insured deposits and equity capital

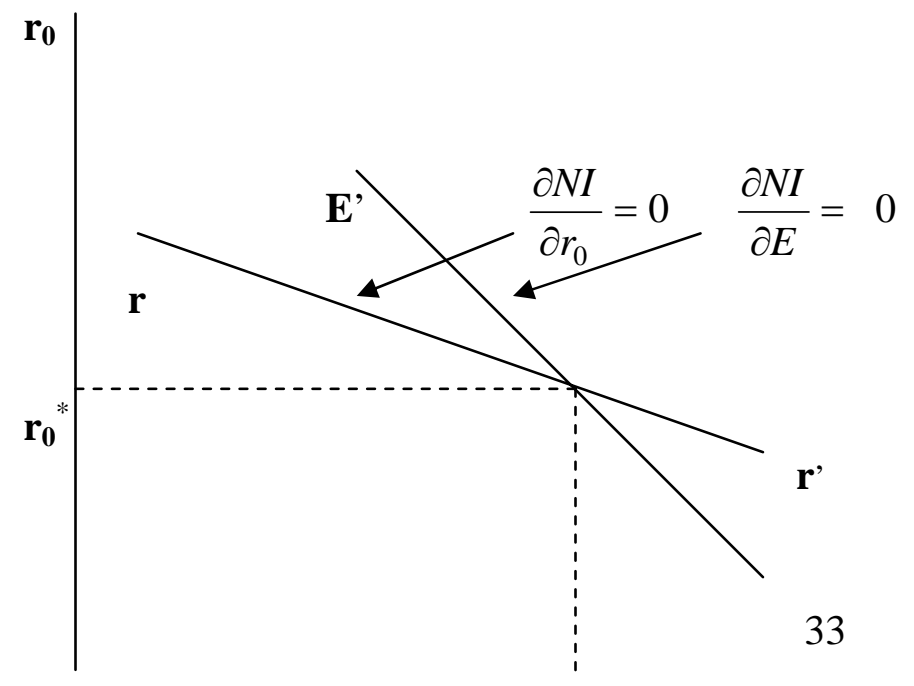




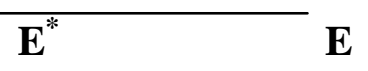

Figure 3

Comparative Statics: Effects of Changes in Parameters on the Optimal Behavior of the Bank

The upward shift of the EE' line in Figure 3a is associated with an increase of $\lambda$ (case1), an increase in the degree of market discipline, $\left|\eta_{E}^{r_{1}}\right|$ (case 4), and an increase of the probability of survival of the bank P (risk decline) (case6).

The downward shift of EE' in Figure $3 \mathrm{~b}$ is associated with the introduction of a risk adjusted insurance premium (case 2) and an increase in the marginal cost of equity, k' (case 5)

The upward shift in rr' in Figure 3c is associated with an increase in competition in the uninsured deposit market, $\eta_{r_{0}}^{D_{0}}$.

$\underline{3 a}$

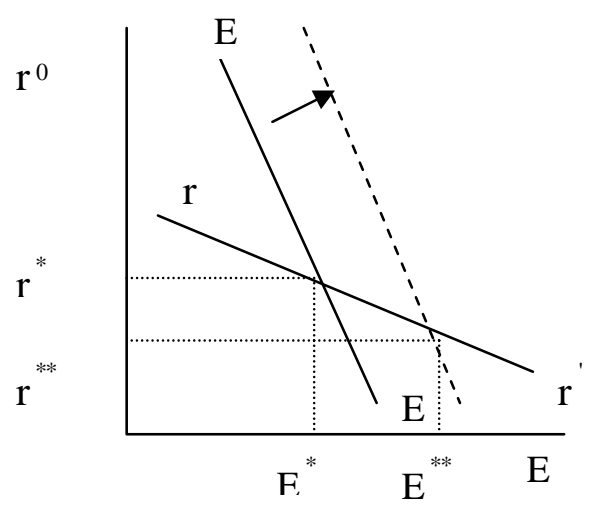

$\underline{3 b}$

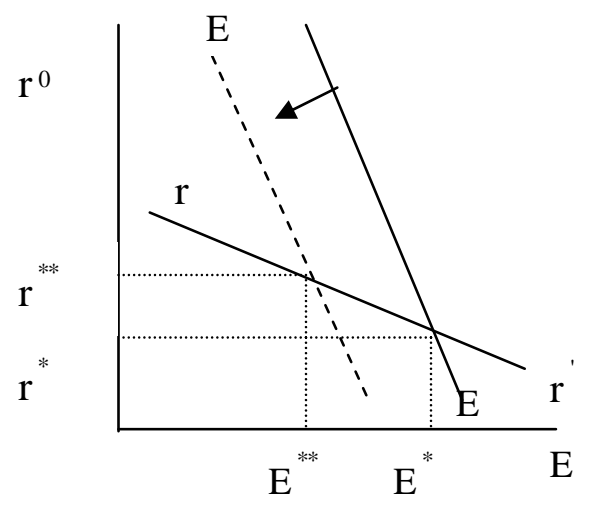

$\underline{3 c}$

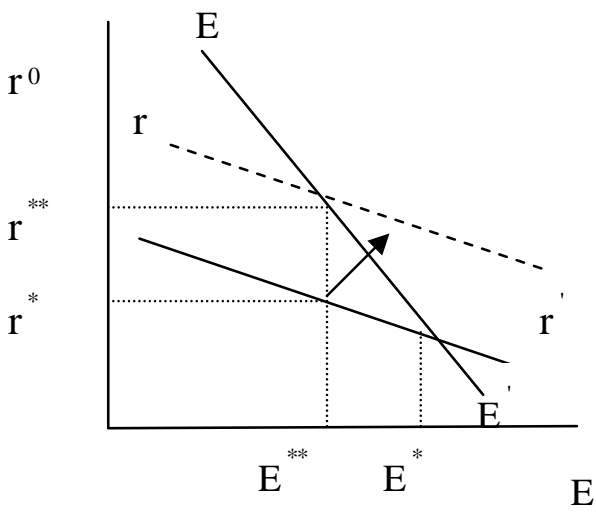


